Health Informatics 
More information about this series at http://www.springer.com/series/1114 
Thomas Wetter

\section{Consumer Health Informatics}

New Services, Roles, and Responsibilities

With contributions by

George Demiris, Amanda K. Hall, Andrea Hartzler, Jina Huh, Georgios Raptis and Lisa M. Vizer 


\author{
Thomas Wetter \\ Institute for Medical Biometry \\ and Informatics \\ University of Heidelberg \\ Heidelberg, Germany \\ Department of Biomedical \\ Informatics and Medical Education \\ University of Washington School of Medicine \\ Seattle, WA, USA
}

ISSN 1431-1917

Health Informatics

ISBN 978-3-319-19589-6

DOI 10.1007/978-3-319-19590-2
ISSN 2197-3741 (electronic)

\section{ISBN 978-3-319-19590-2 (eBook)}

Library of Congress Control Number: 2015942896

Springer Cham Heidelberg New York Dordrecht London

(C) Springer International Publishing Switzerland 2016

This work is subject to copyright. All rights are reserved by the Publisher, whether the whole or part of the material is concerned, specifically the rights of translation, reprinting, reuse of illustrations, recitation, broadcasting, reproduction on microfilms or in any other physical way, and transmission or information storage and retrieval, electronic adaptation, computer software, or by similar or dissimilar methodology now known or hereafter developed.

The use of general descriptive names, registered names, trademarks, service marks, etc. in this publication does not imply, even in the absence of a specific statement, that such names are exempt from the relevant protective laws and regulations and therefore free for general use.

The publisher, the authors and the editors are safe to assume that the advice and information in this book are believed to be true and accurate at the date of publication. Neither the publisher nor the authors or the editors give a warranty, express or implied, with respect to the material contained herein or for any errors or omissions that may have been made.

Printed on acid-free paper

Springer International Publishing AG Switzerland is part of Springer Science+Business Media (www. springer.com) 


\section{Foreword}

After years in the making, consumer health informatics is coming of age. People measure their physiological reactions, monitor their diets, network with others, track their physical activity, search the Internet, communicate with clinicians, and otherwise use information technologies to support taking care of themselves. Enthusiastic reports tout this key area of health informatics as the way to patient empowerment and improved health care. In this welcome and refreshingly balanced book, Thomas Wetter thoughtfully reflects on the promise and potential of these new technologies and examines attendant social changes and ethical considerations.

This book was some years in the making. Thomas had been working on it since before he asked me to participate in a panel at the 2013 American Medical Informatics Association (AMIA) Annual Symposium [1]. He became cochair of the International Medical Informatics Association's Working Group on Consumer Health Informatics in 2007 and chair in 2010. The group's focus on, in the 1996 words of the US General Accounting Office, "the use of modern computers and telecommunications to support consumers in obtaining information, analyzing unique health care needs and helping them make decisions about their own health" dates from its founding in 2000 [2]. AMIA's Consumer and Health Evaluation Working Group (renamed the "Consumer Health Informatics Working Group" and, most recently, the "Consumer and Pervasive Health Working Group") already was operating. Then-president Patricia Flatley Brennan asked me to head a Consumer Informatics Task Force to help guide AMIA more into this emerging area. The following year, AMIA's 2000 Spring Congress included a track on consumer health informatics. It was apparent that patients could be empowered and enlightened while forging new relationships with providers by using computers [3].

During the previous ten years, investigators had developed a variety of applications. They were for medication adherence, smoking cessation, appointment reminders, health behavior counseling, and more. By 2004, consumer health informatics was mature enough for Springer books highlighting the accomplishments. Springer published Consumer Informatics: Applications and Strategies in Cyber Health Care. Its preface credited pioneers of the previous decade, including Warner Slack and Thomas Ferguson, who presented a tutorial at the 1993 AMIA annual 
symposium. Tom Ferguson coined the term "consumer health informatics" [4]. Consumer Health Informatics: Informing Consumers and Improving Health Care, to which I contributed, came out the following year [5]. Investing in eHealth: What It Takes to Sustain Consumer Health Informatics followed soon after [6]. Such books included chapters on patient empowerment and collaborative health care, designing and delivering patient-centered information, home care technologies, patient perspectives and expectations, patient-patient and patient-provider communication, ethical issues, evaluation methods, privacy and security, implementation models, and case studies.

Interest kept growing and technologies kept developing. Companies and health care organizations set up patient portals, personal health records, and social networks among patients. More and more, people got and shared health information from the Internet and Web-based services. In the USA, the 2009 Health Information Technology for Economic and Clinical Health (HITECH) Act promoted electronic medical records. They were envisioned to be linked eventually to patient portals, personal health records, and other patient-provided information. Part of the Patient Protection and Affordable Care Act of 2010 established the Patient-Centered Outcomes Research Institute (PCORI) with a mandate "to improve the quality and relevance of evidence available to help patients, caregivers, clinicians, employers, insurers, and policy makers make informed health decisions." Patients were included in order to ensure that PCORI focused on questions and concerns patients considered most relevant [7]. Health-related smart phone applications and wearable devices became popular, and Springer published a recent volume on mHealth [8].

Consumer Health Informatics: New Services, Roles and Responsibilities reflects the burgeoning interest in meeting collaborative health information needs of consumers and providers. It admirably achieves several purposes. For those wanting an overview of consumer health informatics, it provides a helpful classification scheme based on the roles of consumer and clinician. It also gives a detailed accounting of numerous studies, products, applications, and trends that characterize the consumer health informatics landscape.

In addition, this book contributes to many areas laid out at early conferences and the founding of the IMIA and AMIA Consumer Health Informatics Working Groups. Chapter after chapter, it addresses topics brought to attention then and still being discussed [3]. Thomas carefully tests and explores both visible and behindthe-scenes aspects of using the technologies. He skillfully dissects what consumers may not know about sources of information they are being provided, contracts to which they are agreeing, and potential effects of applications they are using. He provides pointers to improve usability. As a result, readers can make wiser decisions about the whats and hows of the range of applications and technological platforms. Thomas's careful and insightful work provides a model for others.

But this book does far more by interweaving a constant thread of ethics into the discussion. Thomas starts with his concern for patients and what will become of them as an aging population faces a shortage of in-person care. His underlying compassion and patient-centeredness permeate this book. He explores social, ethical, and legal issues together with health consequences in consumer health informatics. He laudably goes beyond the more common topics of privacy, licensure, 
and regulation, though they, too, are well discussed. For Thomas, patients come first. Their feelings, capabilities, needs, opportunities, achievements, and outcomes are paramount while he also highlights potential risks and limitations of the ways the technologies can be used. I became more sensitive to these concerns when interviewing participants in a trial involving a patient-facing application $[9,10]$. I believe them pressing enough to have since reviewed general ethical issues as well as legal ones [11-13]. Thomas's thoughtful tempered analysis is an important contribution to these growing areas of health information technology ethics.

This volume not only fills a gap in the literature but also lays out ways to think about issues in health informatics. These issues come to the fore in consumer health informatics, but need to be addressed more generally. I know readers will find, as I do, that this comprehensive and useful book is a valuable addition to our field.

New Haven, CT, USA

2015

Bonnie Kaplan, PhD, FACMI

Yale University

\section{References}

1. Wetter T, van Voorhees B, Kaplan B, DeMuro PR, Waldo AB. Ethical, legal, and policy barriers to unleashing the full power of consumer health informatics for care delivery. In: American medical informatics association annual symposium, Washington, DC, Nov 2013. Available at http://knowledge.amia.org.

2. http://www.imia-medinfo.org/new2/GA/2012beijing/1210GA-beijing\%20-vp-wgsig-reports. pdf. Accessed 19 June 2015.

3. Kaplan B, Brennan PF. Consumer informatics supporting patients as co-producers of quality. JAMIA (J Am Med Inform Assoc). 2001;8(4):309-16.

4. Nelson R, Ball M, editors. Consumer informatics: applications and strategies in cyber health care (health informatics). Berlin/Heidelberg: Springer; 2004.

5. Lewis D, Eysenbach G, Kukafka R, Stavri PZ, Jimison H, editors. Consumer health informatics: informing consumers and improving health care. Berlin/Heidelberg: Springer; 2005.

6. Gustafson DH, Brennan PF, Hawkins RP, editors. Investing in eHealth: what it takes to sustain consumer health informatics. Berlin/Heidelberg: Springer; 2007.

7. http://www.pcori.org/about-us. Accessed 20 June 2015.

8. Malvey D, Slovensky DJ. mHealth: transforming healthcare. Berlin/Heidelberg: Springer; 2014.

9. Kaplan B, Farzanfar R, Friedman RH. Research and ethical issues arising from ethnographic interviews of patients' reactions to an intelligent interactive telephone health behavior advisor system. In: Ngwenyama O, Introna L, Myers M, DeGross JI, editors. New information technologies in organizational processes: field studies and theoretical reflections on the future of work. Boston: Kluwer Academic; 1999.

10. Kaplan B, Farzanfar R, Friedman RH. Personal relationships with an intelligent interactive telephone health behavior advisor system: a multimethod study using surveys and ethnographic interviews. Int J Med Inform. 2003;71(1):33-41.

11. Kaplan B, Litewka S. Ethical challenges of telemedicine and telehealth. Camb Q Healthcare Ethics. 2008;17(4):401-16.

12. Kaplan B, Selling health data: de-identification, privacy, and speech. Camb Q Healthcare Ethics. 2015;24(3):256-71.

13. Kaplan B. How should health data be used? Privacy, secondary use, and big data sales. Camb Q Healthcare Ethics. (in press). 



\section{Preface}

When I had joined Heidelberg University in 1997 and had developed the classes I was supposed to teach, I started looking around for a long-term challenge that should guide my efforts for the next couple of years. It was the time when large companies sent best agers in droves into early retirement because so many young applicants would fill the ranks and cost less salary. It was, however, also the time of the first reports, e.g., by OECD, that warned of a thinning workforce and an avalanche of retirees. Being in health care and knowing that the avalanche of retirees meant an avalanche of patients, I came to the conclusion that "Affordable Health for Aging Societies" should be my mission. AHAS was written in block letters on my white board to always remind me.

But how to proceed? Before it had taken concrete shape on my mind, I attended a health IT conference in Portland (OR) and heard Enrico Coiera give a keynote address that mounted to the conclusion that, to let the health care system survive the avalanche, $80 \%$ of medical care would have to be self-service medicine in 2020 .

Well, keynote is keynote. But Enrico's central idea was crystal clear to me immediately: My mission would be employing ICT to enable the patient to actively play a safe role in his health care. This is what had been coined Consumer Health Informatics a few years before.

Meanwhile, Consumer Health Informatics is coming of age. Being twenty-some years old it should find its place in health care not too far in the future. I dearly hope that this volume will be instrumental to that end because I believe that from the facts and conclusions about the diminishing future health care workforce, a moral obligation for health professionals to pursue Consumer Health Informatics can be deduced. Following a keynote that Ted Shortliffe gave at the AMIA Annual Symposium 2013 "Informatics Is a Health Profession": We as a health information profession are not marginal but central to this end. The moral obligation that I feel has been among my personal motives to keep pushing for quite a while to finish this book. It is summarized in the very last section of the book (Sect. 17.12). It builds on progress and consolidation in many fields also covered in this volume.

I believe that this is a necessary book because the field still is in a chaotic state. This is evident from Sect. 1.6 and from countless partially contradictory examples. 
Well, chaos is not bad in its own right. Great ideas can emerge from chaos. However, when it becomes serious in terms of patient safety, we should at least understand, better, control the chaos. The field is not only at chaos but also wildly dispersed. This relates to the journals where scholarly articles are published (cf. Sect. 1.6.4) and also to numerous underwhelming funding and business models, while the preferred stakeholders (health plans or governments, depending on model of health care finance) are reluctant to commit themselves.

Despite all these concerns it seems doable. So many experiments presented in this volume show promising results, and our understanding of how to address risks grows (cf. Sect. 17.11). And there are great opportunities beyond attenuating the effects of the future health care workforce shortage. Rather than just offering approved knowledge and supporting approved procedures, Consumer Health Informatics sets out to become an independent source of new knowledge (cf. Sects. 6.3.3 and 9.10.3).

A book like this cannot be written in one year. It actually took more than five years, with some on and off due to other obligations that a full professor has. That seems to imply that some parts are five years old, some five days. This is true and false at the same time. It is true that some chapters were conceived five years ago and some three months ago. That seems to imply that some chapters are outdated, while others are up to date. This, again, is true and false at the same time. It is true that not each and every paragraph reflects the absolutely newest state. Rather did we, my coauthors and myself, do our best to write a principled account of the field. We developed arguments about opportunities and risks, methods for safety, effectiveness, human comprehension and literacy, etc. and identified examples that would underline our arguments and illustrate our methods. Some examples indeed vanished while we wrote whereas others came into existence. But the principles and methods do not expire within a pentad. We hope that ours hold for a decade (or so). If that is the case the book will have its value for another five years (or so). The reader can bring up his own new examples and match them against the arguments and methods. As time passes he will find examples that no longer match. That is why we as authors should start now with the next edition. If our spouses allow.

A book like this cannot be written without many people's help and backing up. First of all I have a great publisher. Early on Grant Weston has given me the confidence that I can concentrate to write a nice book and that Springer would make it look nice. Which saved me days, if not weeks, to tweak out millimeters and points to squeeze content on a page. Grant has also given well-appreciated advice where to allocate and where to withdraw effort. And his patience with my ongoing delays was incredible.

I had numerous people who gave their advice in various forms, many serving as critical chapter readers or pointing me to priceless resources. They are (in alphabetical order, and I dearly hope that I do not miss anybody):

- Michael Ashton

- Axel Bauer

- Leslie Berger 
- Mike Conway

- Paul Fearn

- Sebastian Grommes

- Marten van der Heijden

- Konstantin Kinzel

- Tugba Kutun

- Marion and Joachim Lammarsch

- Tom Moore

- Peter Nawroth

- Alexander Rieß

- Lou Ann Scarton

- Ulla Wetter

- Gaby Wildenbos

- Thomas Willert

Furthermore I received wonderful feedback and challenges from the students in my classes that I taught in Salt Lake City, Amsterdam, Brisbane, Seattle, and Heidelberg.

My two academic homes also contributed magnificently. I had and still have wonderful discussions with my colleagues in Seattle with Wanda Pratt and Andrea Hartzler giving the most inspired impulse. I also found many articles in the UW electronic library that were nowhere else at my disposal. My colleagues in Heidelberg and Heilbronn tolerated delays and timeouts that I took to an extent that went far beyond what can be expected. Our department head Petra Knaup kept encouraging me and mildly pushing me and never lost her patience.

But above and before all, my family has tolerated my mental absenteeism with unbelievable patience. My parents Paul and Irmgard Wetter, nee Michels, passed away too early to see it finished. They would have been so proud. My grandchildren Josua, Daniel, and Timon probably do not remember at all that there was a time when grandpa was not writing a book. My children Anne-Mareike, Miriam, Marius, and Daria do remember, but they, too often, did not dare ask or involve me in activities that took more than a couple of hours.

Comes my beloved wife of nearly forty years, Angelika. For her, I was next door and still far away half an eternity. She has kept things going and has backed me up where I was in charge and whenever I felt really bad comforted me "We'll do it after the book."

\section{Angelika, thank you a thousand times.}

Heidelberg, Germany

Thomas Wetter

March 28, 2015 



\section{Contents}

\section{Part I Introducing the Domain and Levels of Service}

1 Character of Domain and Organization of Book .................. 3

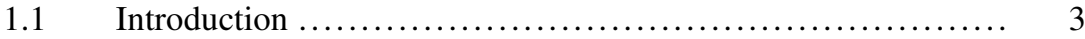

1.1.1 Pioneers ...................................... 3

1.1.2 An Inspiration ................................ 4

1.2 Consumer Health Informatics as a Discipline ................ 5

1.2.1 What Defines Consumer Health Informatics? Helpful Terms ...................... 5

1.2.2 Consumer Health Informatics as a Scientific Discipline ........................... 6

1.2.3 Consumer Health Informatics as Range

$1.3 \quad$ Core Methodology ........................................ 11

1.3.1 Search Support .............................. 11

1.3.2 Data Sharing ................................ 11

1.3.3 Interface Design............................. 12

1.3.4 User Assessment and Personalization ............... 13

1.3.5 End User Participation ........................... 14

$1.4 \quad$ Supportive Methodology ................................ 14

1.4.1 Evaluation .................................... 14

1.4.2 Going Life .................................. 16

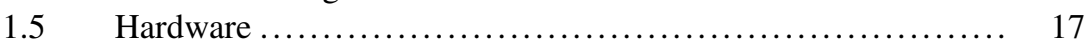

1.5.1 Voice and Sound $\ldots \ldots \ldots \ldots \ldots \ldots \ldots \ldots \ldots \ldots \ldots \ldots \ldots \ldots \ldots \ldots \ldots \ldots \ldots \ldots$

1.5.2 Biosignals .................................. 17

1.5.3 Pointing and Virtual Space ....................... 17

1.5.4 Positioning ................................... 18

1.5.5 Smart Phones................................... 18

1.6 Where in the Literature is Consumer Health Informatics?....... 19

1.6.1 Fruitless Search for MeSH Keywords ................ 19

1.6.2 Opportunistic Search in PubMed................... 20 
1.6.3 Estimated Growth Rates ..................... 20

1.6.4 Scatter Across Media ............................ 22

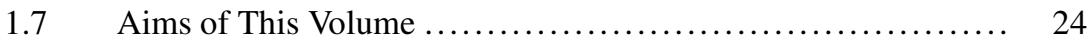

1.7.1 Positive Attitude: We Need It ................... 24

1.7.2 Wide Perspective: It Can Be Done ............... 25

1.7.3 Sound Methodology: How It Should Be Done ........ 25

$1.8 \quad$ Organization of the Book in Detail ....................... 26

1.8.1 Organization of the Book: Part I ................. 26

1.8.2 Organization of the Book: Part II ................ 27

1.8.3 Organization of the Book: Part III ................. 28

1.9 Additional Topics Worth Individual Chapters Under

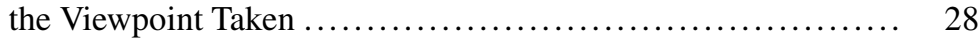

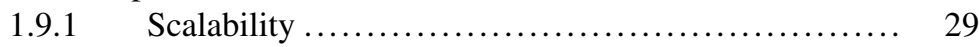

$\begin{array}{ll}1.9 .2 & \text { Disparity } \ldots \ldots \ldots \ldots \ldots \ldots \ldots \ldots \ldots \ldots \ldots \ldots \ldots \ldots \ldots\end{array}$

1.9.3 Public Health ................................ 29

1.9.4 Rare Diseases ................................ 29

1.9.5 Applications ................................ 30

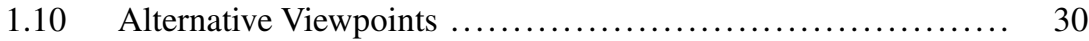

1.10.1 Transient Stimuli and Funding Programs ............. 30

1.10 .2 Devices .................................... 31

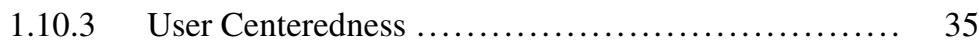

References................................................. 37

2 Economy 1: Immanent Mismatch Between Demand and Supply of Health Care Workforce $\ldots \ldots \ldots \ldots \ldots \ldots \ldots \ldots \ldots . \quad 39$

$2.1 \quad$ Introduction .......................................... 39

2.2 Methodological Considerations ........................... 40

2.2.1 Criteria to Select Variables ...................... 40

2.2.2 Criteria to Select Nations ........................ 41

2.2.3 Criteria to Select Information Resources ............ 41

2.2.4 Base Figures and Derived Indicators of Health Care Demand and Supply ............... 42

2.2.5 The "Best Case" Strategy of Selection............... 44

$2.3 \quad$ Sources and Results ................................ 45

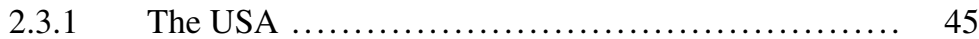

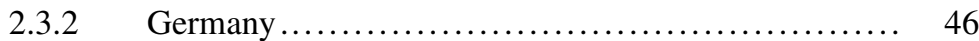

2.3.3 US: German Differences ....................... 49

2.3.4 Challenging the Assumptions ..................... 50

$2.4 \quad$ Options to Match Supply and Demand ................... 52

2.4.1 Rationing .................................... 53

Volume Increase at Equal Cost, with
Quality at Risk .............................. 54

2.4.3 Reduced Effort per Case Through Quality Improvement ............................ 54 


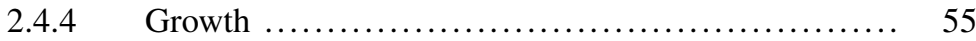

2.4.5 Diversification of Delivery .................... 56

2.5 Benefits from Growth in Other Industries and Segments ....... 57

References........................................... 58

3 Level 0: Searching - Finding - Trusting - Acting - Risking

One's Life? .............................................. 61

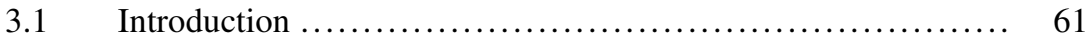

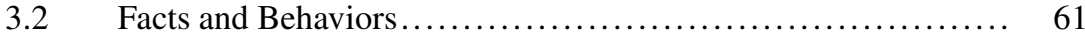

3.2.1 Trends of Utilization of the Internet and Other Media ............................. 61

3.2.2 Increasing Compliance Meets Declining

Comprehension ................................ 62

3.3 Effects, Risks, and Adverse Effects ...................... 63

3.3.1 Searching: Finding?....................... 63

3.3.2 True Risks ................................. 71

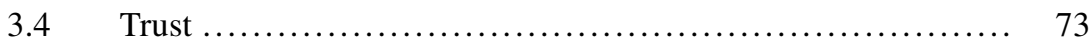

3.4.1 Trust as a Basic Human Notion ................. 73

3.4.2 Innate Instincts and Their Reincarnation in the Digital Age ............................. 73

3.4.3 Trustmarks ................................. 75

3.5 Trustworthy Providers: More or Less .................... 76

3.5.1 NIH and Its Organisations ..................... 76

3.5.2 Wikipedia's and MedlinePlus's Contents ............ 78

$3.6 \quad$ A Short Note on apps ................................ 79

References.................................................. 80

4 Level 1: Enhancing the Provider - Client Relation

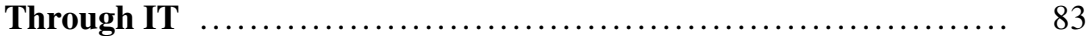

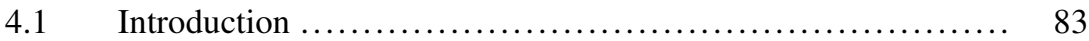

4.2 Level 1 Consumer Health Informatics Versus Telemedicine .... 84

4.3 Incorporating New Media into Patient-Physician

Communication ........................................ 84

4.3.1 E-Mail ......................................... 84

4.3.2 Social Networks............................ 86

4.3.3 Electronic Health Records ....................... 88

$4.4 \quad$ Condition Specific Services ........................... 90

4.4.1 Discharge Management and Follow-Up Care ........ 90

4.4.2 Managing Chronic Diseases..................... 92

4.5 A Short Note on apps ............................... 96

4.5.1 Customer Relationship apps .................... 96

4.5.2 Condition Specific apps ....................... 97

References ................................................... 98 
$5 \quad$ Level 2: Services Without In-Person Contact Between

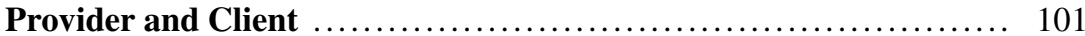

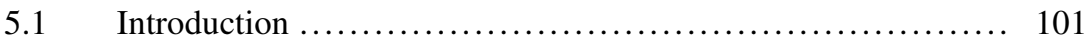

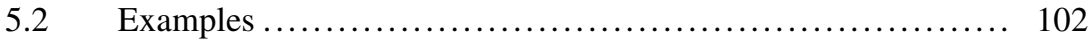

5.2.1 Health Awareness ............................... 102

5.2.2 Mental Health Coaching .......................... 103

5.2.3 Somatic Diseases ............................ 110

5.2.4 Online Pharmacies ............................ 114

5.2.5 Online Counseling ............................ 118

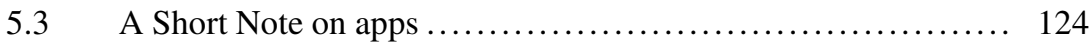

5.3.1 Information Broker apps...................... 124

5.3.2 Logistics Support apps ......................... 125

$5.3 .3 \quad$ Reminders .................................. 125

5.3.4 Condition Specific apps ......................... 126

$5.4 \quad$ Variety of Service Characteristics ....................... 130

5.5 Considerations on Scaling Up .......................... 131

References........................................... 133

6 Level 3: Patient Power on the Web: The Multifaceted Role of Personal Health Wisdom ............................... 135

6.1 Conceptualizing the Wisdom of Patients: A Unique Value Proposition .................................. 135

6.2 Exchanging Patient Wisdom Online: An Evolving Landscape of Social Media ............................ 136

6.2.1 Interacting Through Internet Forums .............. 137

6.2.2 Capturing Knowledge Through Blogs .............. 137

6.2.3 Building Collective Wisdom Through Wikis .......... 138

6.2.4 Collaborating Through Social Networking Tools ...... 139

6.3 Leveraging Patient Wisdom: Varied Levels of Use Among Individuals, Groups, and Crowds ................. 140

6.3.1 Individual Level: From Foraging Alone to Shared Experience .......................... 141

6.3.2 Group Level: From Shared Experience to Collaborative Bricolage...................... 142

6.3.3 Crowd Level: From Collaborative Bricolage to Collective Discovery ................ 143

$6.4 \quad$ Conclusion .............................................. 144

References................................................ 144

7 Distinctive Features of Services Conveyed Through

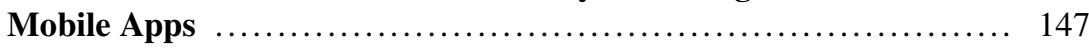

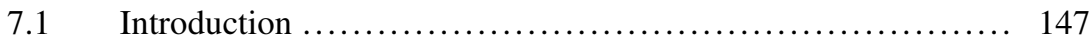

7.2 Values Added Through the Technology ..................... 147

7.3 Distributors' Take on Medical Quality ...................... 149

7.4 Clients' Traps and Barriers in Checking Quality ............. 151 
7.5 Further Necessary Precautions When It Becomes

Serious Medicine......................................... 152

References.............................................. 154

\section{Part II Building Safety Nets Around the Active Client}

8 Dimensions of Patient Risks and Requirements for Patient Safety ... 157

8.1 The Client as Resource ............................. 157

8.2 High Stakes and High Demands ....................... 158

8.3 Outline of the Assessment Scheme ........................ 159

8.4 Overview of Assessment Dimensions ..................... 163

8.4.1 Medical Risk ................................... 163

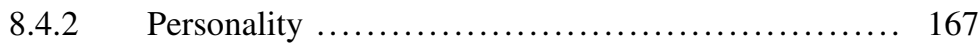

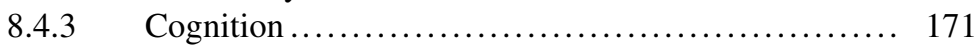

8.4.4 Identity and Authentication ...................... 183

8.5 Further Reading ..................................... 186

References................................................ 186

9 Services for All Stages of the Metabolic Syndrome and Its

Consequences ............................................. 189

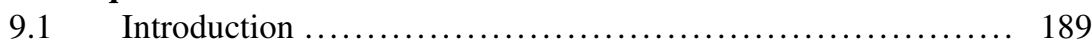

9.2 Diabetes Pioneers: The IDEATel Project .................. 189

9.3 Outline of Chapter ................................. 190

9.4 Risk Awareness and Primary Prevention ................... 191

9.4.1 Fostering Awareness ............................ 191

9.4.2 Turning Awareness into Risk Avoiding Behavior ...... 193

9.5 Treatment Support and Coaching ...................... 200

9.5.1 Simple Tight Medical Guidance ................. 200

9.5.2 Medical Guidance and Tailored Behavioral

9.5.3 Tight Medical Guidance and Behavioral Coaching .... 202

9.5.4 On the Way to Automated Insulin Dosing ............ 203

$9.6 \quad$ Fostering Self Management ........................... 205

9.6.1 In Search of Factors for Services to Last ............ 206

9.6.2 Building a Service That Reflects Own Experiences.... 207

9.6.3 Exploring the Consequences of Smart

Phone Ubiquity ................................ 209

9.7 Complications Management $\ldots \ldots \ldots \ldots \ldots \ldots \ldots \ldots \ldots \ldots \ldots . \ldots \ldots$

9.8 Attenuation of Comorbidities ........................... 211

9.9 Adding Level 3 Self Support .......................... 212

9.10 Concluding Remarks............................... 213

9.10.1 Collateral Benefits .............................. 213

9.10.2 New Options on the Horizon .................... 213

9.10.3 Visitors and Responders: Research Questions......... 213

References........................................... 214 
10 Basic Services Reach Out Towards Under-Served Populations ...... 217

$10.1 \quad$ Introduction ........................................... 217

10.2 Short Text Based Messages: SMS ..................... 217

10.2.1 Public Health Outreach ....................... 218

10.2.2 Unidirectional Behavioral Stimuli ................ 220

10.2.3 Client Initiated Request Processing .............. 224

10.2.4 Closed Loop Services....................... 226

10.2.5 Enhancing Complex Therapies.................. 227

10.2.6 Delivery of Test Results ....................... 228

10.3 Interactive Voice Response: IVR ........................ 229

10.3.1 Public Health Outreach .......................... 229

10.3.2 Enhancing Complex Therapies.................. 230

10.3.3 Cognitive Assessment ........................ 231

10.4 A Closer Look at Effectivity ......................... 232

10.4.1 Intervention vs. Other Factors ................. 232

10.4.2 Behavioral vs. Clinical Effect ................... 232

10.4.3 Size and Format of the Intervention Effort ........... 235

10.5 Expanding the Scope ............................... 237

10.5.1 Enhancing the Technology ...................... 237

10.5.2 Involving Clients' Peers .......................... 239

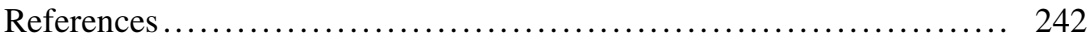

11 Smart Homes: Empowering the Patient Till the End ............. 245

11.1 Overview ......................................... 245

11.2 Smart Home Functionalities ............................... 249

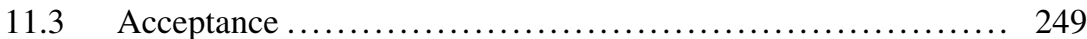

11.4 Ethical Considerations ................................. 250

11.5 The Evidence for Smart Homes ......................... 251

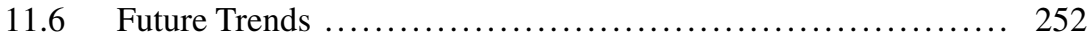

References........................................... 252

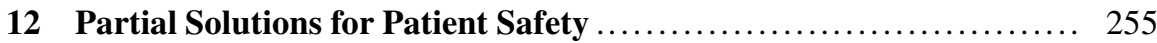

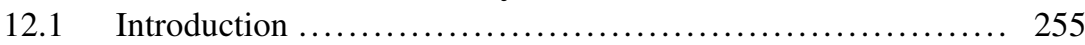

$12.2 \quad$ Medical Risk ........................................ 255

12.2.1 Medical State and History ..................... 255

12.2.2 Identification of Familial Risk ................... 259

12.3 Personality ......................................... 263

12.3.1 Personality Traits ........................... 264

12.3.2 Mental Healthiness ........................... 265

12.3.3 Interfering Attitudes .......................... 266

12.4 Cognition ........................................ 266

12.5 Identify and Authentication ............................ 267

References ............................................... 268 


\section{Part III Additional Methodology}

13 Privacy and Data Protection: Mission Impossible? .............. 273

13.1 Protection of Your Data: Why?............................ 273

13.2 What Data Should Be Protected? ....................... 273

13.3 What Kind of Protection Do We Need? How Can Protection Be Achieved? ................................... 274

13.4 How Health Data and Services Should Be Protected? .......... 275

13.5 The Bottom Line for Companies Running Health Services ..... 277

13.6 Know Your Enemy.................................. 277

13.7 Protection of Your Data: Can I Trust Health Services? ......... 278

References.......................................... 279

14 The Patient-Centered Electronic Health Record and

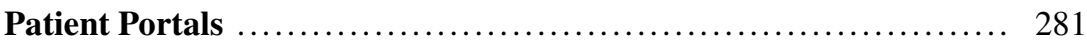

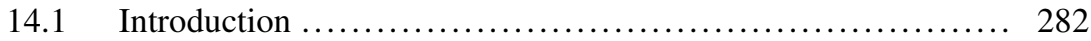

14.1.1 Evolution of Patient-Centered Health

Information Systems in the USA ................ 282

14.2 PHR and Patient Portal Components..................... 283

14.2.1 Data........................................ 284

14.2.2 Functionality ............................... 286

14.3 PHRs and Patient Portals in Context ..................... 287

14.3.1 Political Forces and Meaningful Use ............... 287

14.3.2 Access ....................................... 289

14.3.3 Use and Usability ............................. 289

14.3.4 Liability, Reliability, and Accuracy ................. 291

14.4 Conclusion ......................................... 292

References.......................................... 292

15 Scrutinized Proof of Effectiveness or Cost Effectiveness

Regarding Patient Reported Outcomes ....................... 295

$15.1 \quad$ Introduction . ...................................... 295

15.2 Awareness and Precautions Prior to Beginning a Trial.......... 296

15.2.1 Nature of the "Active Agent"...................... 296

15.2.2 Change Within and Around ...................... 297

15.2.3 Clients' Behavioral Patterns ........................... 298

15.2.4 Control of the Test Setting........................ 304

15.3 Historical Comparisons .................................. 305

$15.4 \quad$ Randomized Controlled Trials .......................... 307

15.4.1 Effectiveness Trials ........................... 308

15.4.2 Cost-Effectiveness Trials ......................... 312

$15.5 \quad$ Noninferiority Trials .................................. 314

15.6 Definite Evidence from Non-randomized Trials ............... 316

15.7 Cochrane: Supreme Evidence Fading ..................... 320 
15.8 After the Trial: Does It Still Work? .................... 321

15.8.1 Non-representative Study Samples................. 321

15.8.2 Prohibitive Effort to Maintain Service Level ......... 322

15.8.3 Arguable Cost-Effect Relation .................. 322

15.8.4 Carving Active Agents ...................... 322

15.8.5 Stakeholder Influence ........................... 323

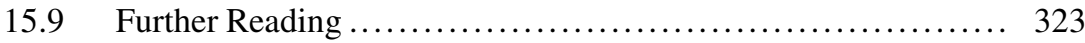

References............................................ 324

\section{Economy 2: Economic Subsistence of Services When}

Research Funding Ends ................................. 327

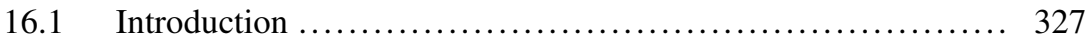

16.2 Client Membership Fees ................................. 327

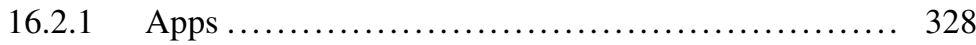

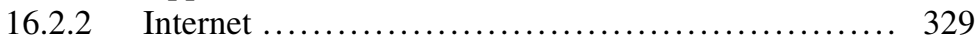

$16.3 \quad$ Client Fees for Service................................. 329

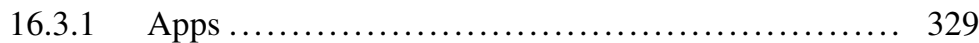

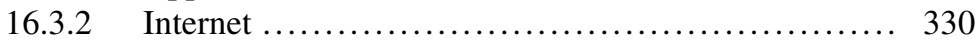

16.4 Heterogeneous Co-branding ............................ 331

16.5 Service-Device Bundles ............................... 332

16.6 Providers' Customer Relationship Services .................. 333

16.7 Online Pharmacies ..................................... 334

16.8 Employer Sponsorship .................................. 335

16.9 Third Party Entrepreneurship ........................... 335

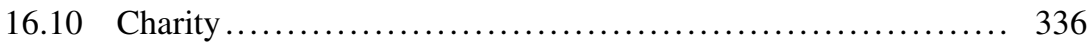

16.11 Government Organisations .............................. 336

16.12 Health Insurance Coverage ............................ 337

References................................................... 338

17 Towards Future Consumer Health Informatics Adapted

Health Care Legislation ..................................... 339

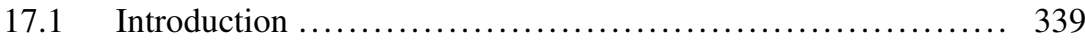

17.2 Frames of Reference ................................... 339

17.3 Legislation, Ethics and Research ........................ 341

17.4 Present Regulations ................................... 342

17.4.1 Structures and Resources in the USA ............... 343

17.4.2 Structures and Resources in Germany ................ 348

17.5 Practice of Medicine, Provision of Information, or Business?... 352

17.5.1 Criteria for Practice of Medicine .................... 353

17.5.2 Criteria for Business ........................... 354

17.6 Present Legislation Meets Present Practice................. 355

17.6.1 US: German Commonalities and Differences .......... 355

17.6.2 Legal Assessment of Present Approaches ............ 356

$17.7 \quad$ Side Entries.............................................. 365

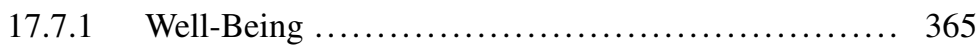

17.7.2 C-Referral ................................. 366 
17.8 Transactions Across Borders .......................... 366

$17.9 \quad$ Health Informatics Professionals Ethics .................... 368

17.10 Research Under Ethical Supervision ..................... 369

17.11 Ethical Considerations for Future Consumer Health

Informatics Legislation ............................. 370

17.11.1 Moral Behavior .............................. 370

17.11.2 Behavioral Codes ........................... 371

17.11.3 Principles Underlying Medical Professional Codes .... 371

17.11.4 Respect for Autonomy ......................... 373

17.11.5 Nonmaleficence ................................ 375

17.11.6 Beneficence ............................... 377

17.11.7 Distributive Justice.......................... 380

17.11.8 Consumer Health Informatics in Utilitarian and Other Theories of Justice ................... 381

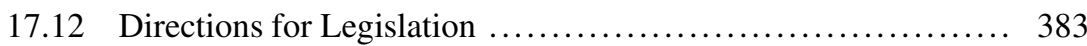

References ................................................ 384

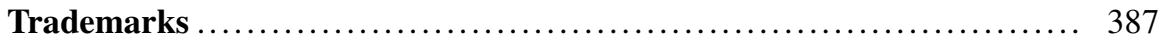

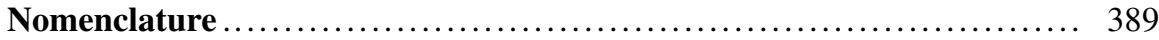

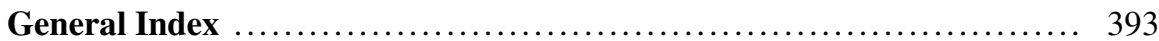

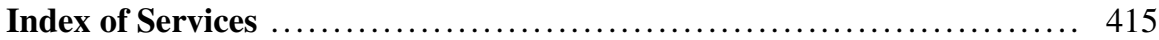

